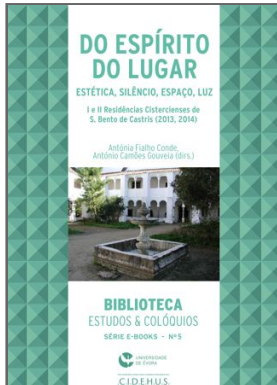

Antónia Fialho Conde and António Camões Gouveia (dir.)

Do Espírito do Lugar - Música, Estética, Silêncio, Espaço, Luz

I e II Residências Cistercienses de São Bento de Cástris (2013, 2014)

\title{
Contributos para o estudo da arquitectura cisterciense, em Portugal, no âmbito do Projecto ORFEUS: forma e música
}

Ana Maria Tavares Martins, Antónia Fialho Conde, Jorge S. Carlos, Fabiel Rodrigues and Carla Reis

Publisher: Publicações do Cidehus

Place of publication: Évora

Year of publication: 2016

Published on OpenEdition Books: 13

septembre 2016

Serie: Biblioteca - Estudos \& Colóquios

\section{Q books}

http://books.openedition.org

\section{Electronic reference}

MARTINS, Ana Maria Tavares ; et al. Contributos para o estudo da arquitectura cisterciense, em Portugal, no âmbito do Projecto ORFEUS: forma e música In: Do Espírito do Lugar - Música, Estética, Silêncio, Espaço, Luz: I e /l Residências Cistercienses de São Bento de Cástris $(2013,2014)$ [online]. Évora: Publicações do Cidehus, 2016 (generated 27 October 2016). Available on the Internet: <http://books.openedition.org/ cidehus/2113>. ISBN: 9782821875029 . DOI: 10.4000/books.cidehus.2113. 
Contributos para o estudo da arquitectura cisterciense, em Portugal, no âmbito do Projecto ORFEUS: forma e música*

\section{Ana Maria Tavares Martins"**, Antónia Fialho Conde***, Jorge S. Carlos ${ }^{* * * *}$, Fabiel Rodrigues ${ }^{* * * * *}$, Carla Reis ${ }^{* * * * * *}$}

\section{Abstract}

This communication reflects the work done in the Department of Civil Engineering and Architecture at the University of Beira Interior (Portugal), and still ongoing, in the framework of the project ORFEUS - The Tridentine Reform and music in the cloistral silence: the Monastery of S. Bento de Cástris (Project FCT EXPL/EPH-PAT/2253/2013) and aims to bring the debate to a contribution to the study of the specificity of the monastery of St. Bento de Cástris in the context of Cistercian architecture, in which the shape and the music are intertwined.

In this way, two dissertations have been developed in Architecture (integrated master course of architecture of the University of Beira Interior) within the project ORFEUS, which are divided by the importance and contributions of the Cistercian Architecture in contemporary religious architecture, the morphology of the Cistercian churches and the relationship between architecture and music in the specific case study of the church of the monastery of St. Bento de Cástris.

Keywords: Cistercian Architecture; church; morphology; S. Bento de Cástris; ORFEUS

\footnotetext{
* Este artigo foi desenvolvido no âmbito de um projecto de investigação financiado pela Fundação para a Ciência e Tecnologia (FCT) com a referência EXPL/EPH-PAT/2253/2013 e intitulado "ORFEUS - A reforma tridentina e a música no silêncio claustral: o mosteiro de S. Bento de Cástris" sendo a instituição proponente a Universidade de Évora, através do Centro Interdisciplinar de História, Culturas e Sociedades (CIDEHUS), e sendo a Universidade da Beira Interior uma das instituições parceiras conjuntamente com a Universidade do Minho e a Universidade dos Açores.

** (DECA-UBI, Lab2PT, CIDEHUS) - é arquitecta e investiga aprofundadamente o património e as arquitecturas de Cister em Portugal, a sua morfologia, inserção no território, sendo autora de vários trabalhos neste contexto e tendo sido responsável pelo estudo do edificado cisterciense de Cástris no âmbito do Projecto ORFEUS.

*** (UÉ, CIDEHUS, CEHR, HERCULES)

**** (DECA-UBI, C-Made) - tem formação base em arquitectura e engenharia civil e a sua investigação recai sobre a reabilitação arquitectónica e urbana, eficiência energética e luz natural, com particular incidência nas arquitecturas de Cister em Portugal, tendo apoiado cientificamente o Projecto ORFEUS.

***** (DECA-UBI) - é um jovem arquitecto que contribuiu para o estudo do legado cisterciense, no âmbito da sua dissertação de mestrado, enquanto output do Projecto ORFEUS.

****** (DECA-UBI) - é uma jovem arquitecta que contribuiu para o estudo do edificado cisterciense de Cástris, e a sua articulação com a música, no âmbito da sua dissertação de mestrado enquanto output do Projecto ORFEUS.
} 


\section{Resumo}

Esta comunicação reflecte o trabalho desenvolvido no Departamento de Engenharia Civil e Arquitectura da Universidade da Beira Interior, e ainda em curso, no âmbito do Projecto ORFEUS - A Reforma tridentina e a música no silêncio claustral: o mosteiro de S. Bento de Cástris (Projecto FCT EXPL/EPHPAT/2253/2013) e pretende-se com esta comunicação trazer a debate um contributo para o estudo da especificidade do Mosteiro de S. Bento de Cástris, no contexto da arquitectura cisterciense, no qual a forma e a música se entrelaçam.

Neste sentido foram desenvolvidas duas dissertações de mestrado integrado em Arquitectura, no âmbito do Projecto ORFEUS, que se repartem pela importância e contributos da Arquitectura Cisterciense na Arquitectura religiosa contemporânea, a morfologia das igrejas cistercienses e a relação entre a arquitectura e música patente no estudo de caso da igreja do Mosteiro de S. Bento de Cástris.

Palavras-chave: Arquitectura Cisterciense, igreja, morfologia, S. Bento de Cástris, ORFEUS

\section{Morfologia das arquitecturas de Cister em Portugal}

Se o Claustro é o epicentro do Mosteiro, em termos arquitectónicos e funcionais, a Igreja $^{2}$ é o coração, o epicentro do "corpus" monástico, isto é, o coração que faz pulsar o sangue que flui para o "ora et labora", é o centro anímico e espiritual do mosteiro. A igreja encontrava-se orientada em direcção ao levantar do sol, ao oriente, e era implantada no ponto mais elevado do vale. A sul encontravam-se ancoradas as demais dependências monásticas. ${ }^{3}$

De um modo geral a igreja cisterciense possui uma planta em cruz latina, disposta na maior parte dos casos no lado norte do mosteiro, assim como apresenta uma ábside direccionada a oriente.

\footnotetext{
${ }^{2}$ Para a definição de Igreja ver: BANGO, Isidro; El monasterio medieval; Ed. Anaya; Madrid; 1990; pp. 42-43 / KINDER, Terryl N.; I Cisterciensi - vita quotidiana, cultura, arte; Biblioteca di Cultura Medievale; col. Di Fronte e Attraverso; $\mathrm{n}^{\circ}$ 468; Editoriale Jaca book spa; Milano; 1998; pp. 89 - 131 / KINDER, Terryl N.; L'Europe Cistercienne; col. Les formes de la nuit; Ed. Zodiaque; 1998 / BORGES, Nelson Correia; Arquitectura Monástica portuguesa na época moderna (notas de uma investigação) in MUSEU; IV série; nº; 1998; pp. 53 - 55; TOBIN, Stephen; Les Cisterciens - Moines et Monastères d’Europe; Les Éditions du Cerf; Paris 1995 ; pp. 88 - 100

${ }^{3}$ MARTINS, Ana Maria Tavares Ferreira; As Arquitecturas de Cister em Portugal. A actualidade das suas reabilitações e a sua inserção no Território. Tese de doutoramento apresentada na Universidade de Sevilha, texto policopiado inédito. Sevilha. 2011.
} 
Deste modo, em forma de cruz latina, a igreja era composta geralmente por três naves sendo a nave central subdividida no coro dos monges (chorus monachorum), antes do transepto, e no coro dos conversos (chorus conversorum).

O coro dos monges ocupa assim as primeiras arcadas da nave central, diante da capelamor, e presbitério, seguindo-se o coro dos conversos (ou também apelidado de retrocoro), que se encontrava separado por uma tribuna ou jubeu. Presbitério (presbiterium) é também o nome pelo qual se designa a Capela-mor, ou melhor o espaço que circunda o altar-mor, e que ganha importância sobretudo a partir do século XVI, no seguimento do Concílio de Trento (1545-1563), assim como outros elementos tais como o púlpito, as capelas laterais e o órgão. ${ }^{4}$

O Jubeu separa assim os coros de monges e de conversos sendo o local a partir do qual se cantavam os salmos de Vigílias e se faziam as leituras da Epístola e do Evangelho. Jubeu provém da frase latina "Jube, Domine, benedicere" que era pronunciada pelo leitor quando subia a este elemento e, antes de iniciar a sua leitura, pedia a bênção ao celebrante. ${ }^{5}$ Os monges enfermos sentavam-se junto ao jubeu e os conversos enfermos sentavam-se próximos do lado poente da igreja. ${ }^{6}$

Os elementos exteriores à comunidade estavam confinados ao lado ocidental da igreja $\mathrm{e}$ às naves laterais.

No que respeita à Igreja na Regra de S. Bento apenas se encontra como referência:

$\mathrm{O}$ oratório seja o que o seu nome indica e nenhuma outra coisa ali se faça ou guarde. Findo

o Ofício Divino, saiam todos em profundo silêncio, possuídos de reverência para com Deus; de modo que, se algum irmão quiser continuar a orar em particular, não seja estorvado pela impertinência de outrem. ${ }^{7}$

Segundo S. Bento o mosteiro é "...uma escola do serviço do Senhor." e a Igreja assumese como ponto fulcral deste microcosmo pois é nela que o monge encontra o sentido da sua vida e concretiza a sua vocação estando em comunhão com Deus através do ofício divino e da liturgia.

\footnotetext{
${ }^{4}$ DIAS, Geraldo Coelho; Os Mosteiros e a organização dos Espaços: Arquitectura e Espiritualidade; texto inédito policopiado; 2006

${ }^{5}$ Cfr. JORGE, Virgolino Ferreira; Organização Espacio-funcional da Abadia Cisterciense Medieva in "Actas do $1^{\circ}$ Encontro Cultural de São Cristóvão de Lafões: As Beiras e a presença de Cister - Espaço, Património edificado, Espiritualidade.”; Sociedade do Mosteiro de São Cristóvão de Lafões; São Cristóvão de Lafões; 2006; p.81

${ }^{6}$ TOBIN, Stephen; Op. cit.; p. 93

${ }^{7}$ Ver capítulo LII R.S.B. in Regra do Patriarca S. Bento; traduzido e anotado do latim pelos Monges de Singeverga; $2^{\mathrm{a}}$ edição; Edições "Ora \& Labora”; Mosteiro de Singeverga; Singeverga; 1992; p. 107

${ }^{8}$ Ver Prólogo in Regra do Patriarca S. Bento; traduzido e anotado do latim pelos Monges de Singeverga; $2^{\mathrm{a}}$ edição; Edições "Ora \& Labora"; Mosteiro de Singeverga; Singeverga; 1992; p. 17
} 
A utilização da igreja difere em muito da das outras ordens monásticas pois os desenvolvimentos da liturgia com as suas missas de intercessão e procissões foram reduzidos de modo avassalador. As consequências desta diferente utilização são perceptíveis no extremo oriental do edifício pois deste modo a capela-mor é quadrangular ladeada por duas capelas alinhadas, ao contrário das outras igrejas onde existiam deambulatórios e capelas radiais, assim como transeptos elaborados. A nave central é frequentemente iluminada por várias aberturas nos tramos perpendiculares ao eixo da igreja. $^{9}$

Nas igrejas cistercienses utilizava-se na sua altura a razão "perfeita" agostiniana de 1:2 como refere von Simson ${ }^{10}$ Com o decorrer do tempo também a própria planta da igreja se vai adaptando a distintos territórios, evoluindo para outras soluções construtivas e novas espacialidades de cunho regional do meio onde se inserem.

Note-se que o coro nos mosteiros femininos apresenta-se de modo distinto pois as monjas estavam obrigadas ao completo isolamento não só do sacerdote como dos demais assistentes do ofício. Assim o coro monástico feminino era separado, por uma grade, a grade de clausura), ou mesmo por uma parede divisória, dos restantes espaços da igreja ou então localizava-se numa galeria sobrelevada em relação à igreja. ${ }^{11}$

O coro das monjas conforma-se no local oposto ao altar-mor, afirmando-se ambos os espaços como dois pólos de fervor religioso. ${ }^{12}$

O cadeiral conforma por fim o coro, sendo de cariz simples ou exuberante podendo assumir diversas disposições: simples, complexa, fiada simples ou dupla em linha ou em U(gráfico). O cadeiral, fosse de cariz simples ou complexo, seria composto por: assento, misericórdia, apoia-mãos, espaldar e coroamento superior, platibandas de apoios de livros.

Deste modo compreende-se que a entrada do templo não seja axial, como nos masculinos, mas sim lateral. No caso dos mosteiros femininos cujo coro se encontrava sobreelevado, a entrada poderia ser axial tal como nos mosteiros masculinos.

Deste modo, no que respeita aos mosteiros cistercienses femininos, apresentam-se três tipos de entradas na Igreja:

I. Acesso lateral:

São deste tipo os mosteiros cujo acesso, de elementos exteriores à comunidade, se faz por uma porta lateral rasgada directamente na parede da Igreja. São deste tipo os Mosteiros de

\footnotetext{
${ }^{9}$ KINDER, Terryl N.; Op. cit.; pp. 92-93

${ }^{10}$ Cit. SIMSON, Otto von; La catedral gótica; Alianza Forma; Madrid; 2000; pp. 68-69

${ }^{11}$ KINDER, Terryl N.; Op. cit.; p. 99

12 BORGES, Nelson Correia; Arquitectura Monástica portuguesa na época moderna (notas de uma investigação) in MUSEU; IV série; nº7; 1998; p.55
} 
Santa Maria de Cós, Nossa Senhora da Assunção de Tabosa e S. Pedro e S.Paulo de Arouca. ${ }^{13}$

II. Acesso através de loggia:

São deste tipo os mosteiros cujo acesso, de elementos exteriores à comunidade, se faz através de uma loggia que conduz a uma porta lateral rasgada directamente na parede da Igreja. São deste tipo os Mosteiros de Santa Maria de Almoster (vestígios), S. Dinis de Odivelas e S. Bernardo de Portalegre. ${ }^{14}$

III. Acesso indirecto com antecâmara:

São deste tipo os mosteiros cujo acesso, de elementos exteriores à comunidade, se faz através de uma antecâmara prévia que conduz à porta da Igreja do mosteiro. São deste tipo os Mosteiros de Santa Maria de Celas, S. Mamede do Lorvão, S. Bento de Cástris e Nossa Senhora da Nazaré do Mocambo. ${ }^{15}$

O transepto confinava com a ábside rectangular, de carácter sólido e austero, era no presbitério que se celebrava a eucaristia. $\mathrm{O}$ transepto permitia dotar a igreja de uma maior espacialidade e luminosidade, permitia também acolher capelas nos seus braços. ${ }^{16}$

Habitualmente a igreja não estava aberta ao público mas no entanto existia uma entrada específica, destinada a elementos exteriores à comunidade, na fachada principal da igreja, era o pórtico ou nártex. O nártex assinala a passagem do mundo terreno ao local de culto sagrado.

Os cistercienses reduziram o pórtico à sua expressão mais simples ao contrário dos cluniacenses. Porém, alguns mosteiros cistercienses apresentam um nártex significativo facto apenas compreendido pelas influências arquitectónicas do local e região onde se inseriam. Tobin refere que:

No que respeita à igreja como um todo, nos mosteiros cistercienses portugueses que chegaram até à contemporaneidade pode-se observar uma vasta utilização de tipologias não ficando apenas vinculada à métrica e desenho claravalense o que vem, uma vez mais, demonstrar o que se vem afirmando: a existência de um plano tipo mas com espaço para a singularidade regional e para a liberdade.

Deste modo, tanto no que respeita aos mosteiros femininos como aos mosteiros masculinos, encontram-se plantas monoaxiais, biaxiais e centralizadas

Deste modo os mosteiros femininos portugueses (Fig. 1) pertencentes à Ordem de Cister apresentam a igreja segundo três tipos distintos, segundo a sua planta:

\footnotetext{
${ }^{13}$ MARTINS, Ana Maria Tavares Ferreira; As Arquitecturas de Cister em Portugal. A actualidade das suas reabilitações e a sua inserção no Território. 2011.p.339

${ }^{14}$ Ibidem, p. 340

${ }^{15}$ Ibidem, p. 340

${ }^{16}$ KINDER, Terryl N.; Op. cit.; p. 109
} 
I. Monoaxial: São deste tipo as igrejas dos mosteiros cuja planta apresenta um único eixo, não possuindo transepto. As igrejas podem ser monoaxiais simples (se possuírem apenas uma nave) ou complexas (se possuírem mais do que uma nave, no caso português, apresentam três naves). São do tipo monoaxial simples (apenas uma nave) as igrejas dos Mosteiros de S. Pedro e Paulo de Arouca, nossa Senhora da Assunção de Tabosa, S. Mamede de Lorvão, Santa Maria de Cós, S. Dinis de Odivelas, Nossa senhora da Nazaré do Mocambo. É do tipo complexo (três naves) a igreja do Mosteiro de Santa Maria de Almoster. ${ }^{17}$

II. Biaxial: São deste tipo as igrejas dos mosteiros cuja planta apresenta dois eixos, possuindo deste modo transepto. As igrejas monásticas femininas deste tipo apresentam-se como biaxiais simples, isto é, possuindo apenas uma nave e um transepto. São do tipo biaxial simples as igrejas dos Mosteiros de S. Bento de Cástris e de s. Bernardo de Portalegre. ${ }^{18}$

III. Centralizada: São deste tipo as igrejas dos mosteiros cuja planta apresenta um foco central. No caso das igrejas monásticas femininas estas apresentam apenas um foco associado a uma circunferência enquanto as igrejas monásticas deste tipo apresentam mais do que um foco pois as suas plantas são elípticas. Deste tipo, apenas o Mosteiro de Santa Maria de Celas apresenta uma planta centralizada. ${ }^{19}$

\footnotetext{
${ }^{17}$ MARTINS, Ana Maria Tavares Ferreira; As Arquitecturas de Cister em Portugal. A actualidade das suas reabilitações e a sua inserção no Território.. 2011.pp.350-351

${ }^{18}$ Ibidem; p. 352

${ }^{19}$ Ibidem; p. 352
} 


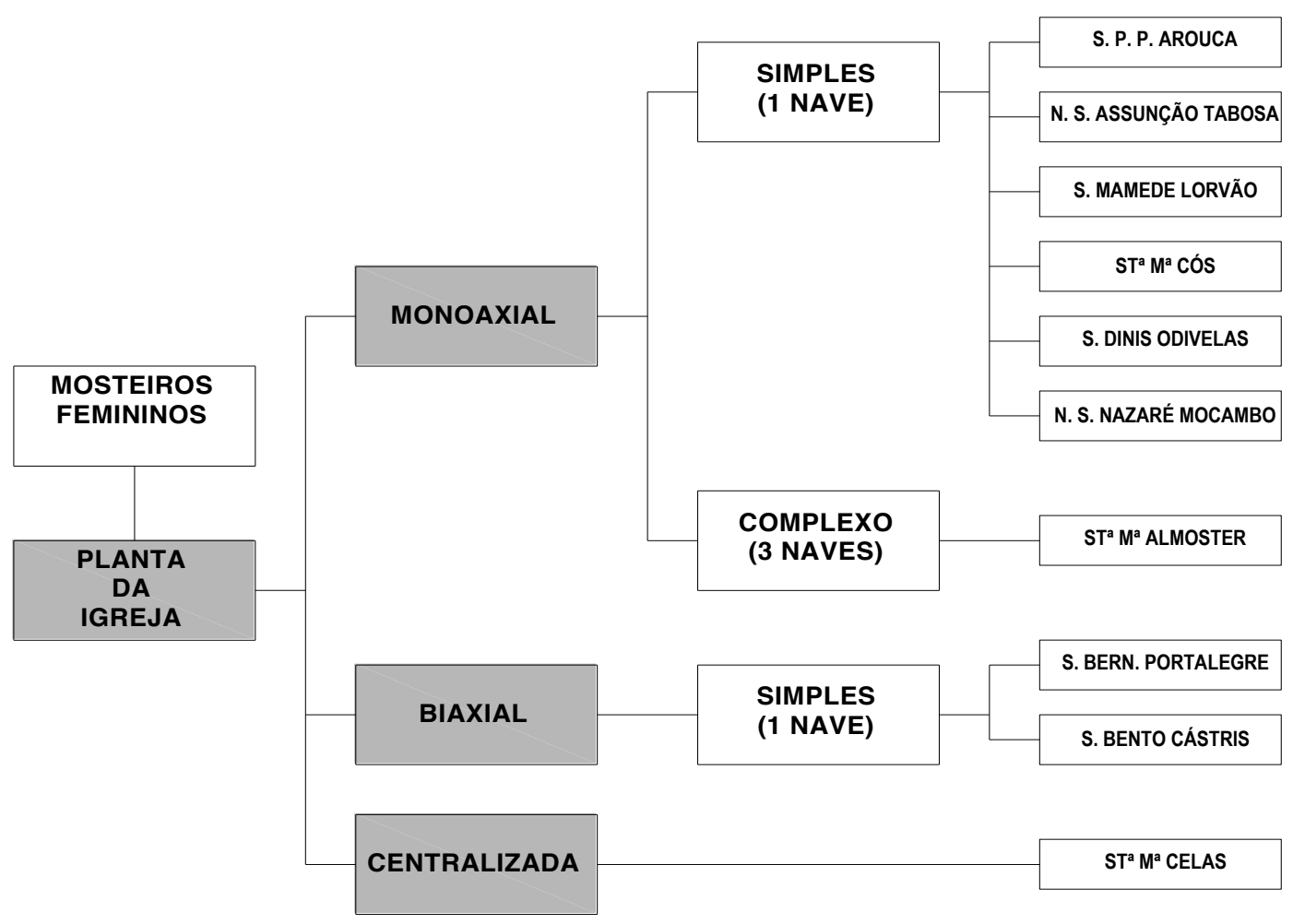

Fig- 1 - 1 Tipologia das plantas das igrejas monásticas cistercienses femininas em Portugal (síntese e esquema retirado de MARTINS, Ana Maria Tavares Ferreira; As Arquitecturas de Cister em Portugal. A actualidade das suas reabilitações e a sua inserção no Território. 2011.p.349)

Tal como os mosteiros femininos portugueses, pertencentes à Ordem de Cister, também os mosteiros masculinos portugueses (Fig.2), pertencentes à mesma Ordem, apresentam a igreja segundo três tipos distintos, segundo a sua planta:

I. Monoaxial:

São deste tipo as igrejas dos mosteiros cuja planta apresenta um único eixo, não possuindo transepto. Como já foi referido para os mosteiros femininos, de igual modo, as igrejas podem ser monoaxiais simples (se possuírem apenas uma nave) ou complexas (se possuírem mais do que uma nave, no caso português, apresentam três naves). ${ }^{20}$

São do tipo monoaxial simples (apenas uma nave) as igrejas dos Mosteiros de Santa Maria do Ermelo (tendo em tempos pertencido ao tipo complexo pois ainda se podem observar as marcas de três naves, agora adaptadas às mais diversas

\footnotetext{
${ }^{20}$ MARTINS, Ana Maria Tavares Ferreira; As Arquitecturas de Cister em Portugal. A actualidade das suas reabilitações e a sua inserção no Território. 2011.p.353-354
} 
necessidades de uma igreja de província, tendo mesmo desaparecido uma das naves $^{21}$ ), Santa Maria das Júnias, S. Pedro das Águias (o velho e o novo), Colégio do Espírito Santo, Santa Maria da Estrela, S. Paulo de Almaziva. É do tipo monoaxial complexo (três naves) a igreja do Mosteiro de Santa Maria de Fiães. ${ }^{22}$

II. Biaxial:

São deste tipo as igrejas dos mosteiros cuja planta apresenta dois eixos, possuindo assim transepto. As igrejas monásticas masculinas deste tipo apresentam-se como biaxiais complexas, isto é, possuindo um corpo de três naves e um transepto. São do tipo biaxial complexa as igrejas dos Mosteiros de Santa Maria de Alcobaça, Santa Maria de Salzedas, Abadia velha de Salzedas, S. João de Tarouca, Santa Maria de Aguiar, Santa Maria de Seiça (vestígios). ${ }^{23}$

Considera-se uma excepção a planta do Mosteiro de Santa Maria do Bouro pois os braços do transepto estão perfeitamente integrados na sequência de nichos de capelas laterais. No entanto como estas capelas apresentam passagens de umas para as outras pode-se admitir a existência em ambos os lados da nave central de uma nave colateral, perfazendo assim as três naves que juntamente com a existência de um transepto fazem parte desta tipologia. ${ }^{24}$

III. Centralizada:

São deste tipo as igrejas dos mosteiros cuja planta apresenta um foco central. No caso das igrejas monásticas femininas estas apresentam mais de um foco associados a uma forma elíptica enquanto as igrejas monásticas femininas deste tipo apresentam apenas um foco. São possuidores de planta centralizada os Mosteiros de S. Cristóvão de Lafões e Santa Maria de Maceira Dão. ${ }^{25}$

\footnotetext{
${ }^{21}$ Para mais informação sobre esta ocorrência consultar: BRAZ, António Manuel da Silva; O Mosteiro e a Igreja de Ermelo; Faculdade de Teologia - Braga (Universidade Católica Portuguesa); Braga; 2009

${ }^{22}$ MARTINS, Ana Maria Tavares Ferreira; As Arquitecturas de Cister em Portugal. A actualidade das suas reabilitações e a sua inserção no Território. 2011.pp.353-354

${ }^{23}$ Ibidem; pp.355-356

${ }^{24}$ Ibidem; p. 355

${ }^{25}$ Ibidem; pp. 357
} 


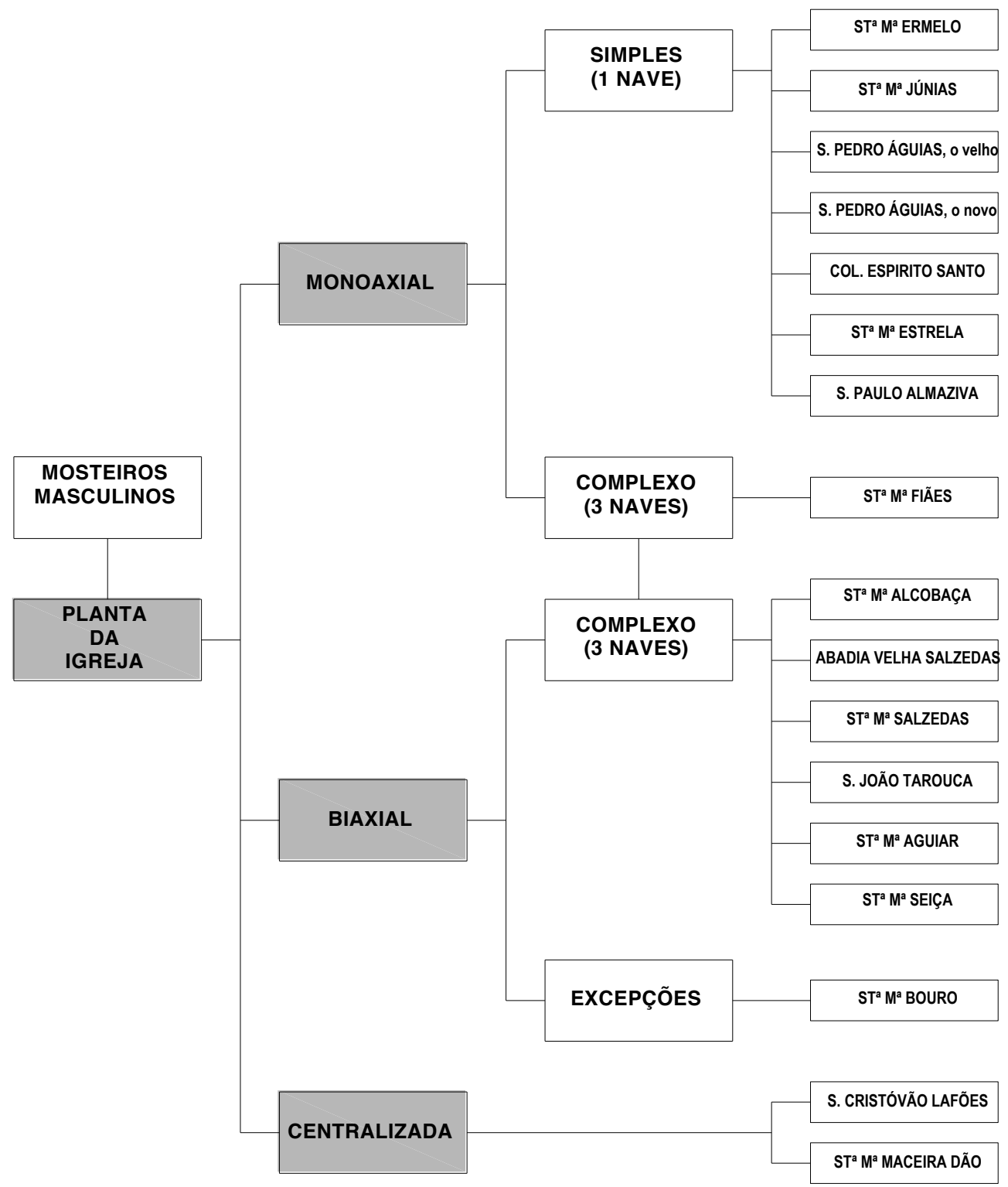

Fig. 2 Tipologia das plantas das igrejas monásticas cistercienses masculinas em Portugal (síntese e esquema retirado de MARTINS, Ana Maria Tavares Ferreira; As Arquitecturas de Cister em Portugal. A actualidade das suas reabilitações e a sua inserção no Território. 2011.p.353)

Trabalho desenvolvido pela ubi no âmbito do Projecto ORFEUS

A inclusão da Universidade da Beira Interior surge no seguimento da participação activa desta instituição na organização de dois eventos científicos que alavancaram a participação da mesma na submissão da candidatura do Projecto ORFEUS - "A Reforma Tridentina e a música no silêncio claustral: o mosteiro de S. Bento de Cástris" à FCT (FCT EXPL/EPH-PAT/2253/2013). Estes eventos foram o "I Simpósio Internacional 
Espaços de Cister: Arquitectura e Memória" ${ }^{26}$ em 2012 e "Residência Cisterciense em S. Bento de Cástris" ${ }^{27}$ em 2013.

De igual modo a parceria e investigação no âmbito de S. Bento de Cástris foi apresentada em comunicações conjuntas tal como é o caso da comunicação apresentada em 2013 no "Encontro Internacional sobre Claustros no Mundo Mediterrânico (Séc. X-XVIII)"28. Tendo como ponto de partida a investigação realizada no âmbito de duas teses de doutoramento, uma em História e outra em Arquitectura (vertente Reabilitação do Património Arquitectónico e Urbano), que se debruçaram sobre a temática cisterciense portuguesa (uma sobre o Mosteiro Cisterciense de S. Bento de Cástris, em Évora, e outra sobre as Arquitecturas de Cister em Portugal) e um centro de investigação comum, o CIDEHUS, foi apresentada uma visão interdisciplinar e de conjunto de todos os claustros cistercienses em Portugal, quer sejam mosteiros femininos ou masculinos, mas destacando a especificidade do Mosteiro de S. Bento de Cástris.

Esta parceria aprofundou-se no evento "Olhares Cruzados sobre o Património Cultural" Encontro de trocas da Linha 2 do CIDEHUS (Universidade de Évora) - Património e Diversidade Cultural Grupo 1: Pi - Património Imaterial e Coesão Social, com a análise de Cister no âmbito da produção científica do CIDEHUS. ${ }^{29}$

Também em Maio esta mesma parceria gerou a organização de uma Sessão no "International Medieval Congress 2014 - Leeds" com o apoio da "Cîteaux: Commentarii cistercienses" tendo sido moderadora Terryl N. Kinder, a editora-chefe da "Cîteaux: Commentarii Cistercienses" ${ }^{30}$

\footnotetext{
26 "I SIMPÓSIO INTERNACIONAL ESPAÇOS DE CISTER: ARQUITECTURA E MEMÓRIA" - 2012/Março/8-9 [organizado pelos Departamento de Engenharia Civil e Arquitectura e Departamento de Letras da Universidade da Beira Interior, co-organizado pela APOC - Associação Portuguesa de Cister e com o apoio da Abadia Cisterciense de Santa Maria de Oseira]; Covilhã: Faculdade de Engenharia da Universidade da Beira Interior (comissão organizadora: Ana Maria Tavares MARTINS, António PEREIRA e José Luis Albuquerque CARREIRAS)

27 "Residência Cisterciense em S. Bento de Cástris" - 2013/Setembro/19-21 - [organizadas pelo CIDEHUS, CHAIA, DRCAlentejo]; Évora: Mosteiro de S. Bento de Cástris (comissão organizadora: Antónia CONDE, Ana Maria Tavares MARTINS, António Camões GOUVEIA e Aurora CARAPINHA)

${ }^{28}$ CONDE, Antónia e MARTINS, Ana Maria Tavares; "Dos Claustros Cistercienses Portugueses: a especificidade de S. Bento de Cástris" in "Encontro Internacional sobre Claustros no Mundo Mediterrânico (Séc. X-XVIII)" organizado pelo Instituto de História da Arte da Faculdade de Ciências Sociais e Humanas da Universidade Nova de Lisboa; Lisboa, Portugal: Museu Nacional de Arte Antiga; 2013/Junho/20-22

${ }^{29}$ CONDE, Antónia Fialho e MARTINS, Ana Maria Tavares; Cister no âmbito da produção científica do CIDEHUS in "Olhares Cruzados sobre o Património Cultural" - Encontro de trocas da Linha 2 do CIDEHUS (Universidade de Évora) Património e Diversidade Cultural Grupo 1: Pi - Património Imaterial e Coesão Social - Coord. Filipe Themudo Barata; Grupo 2: Pm - Património, Cultura Material e Paisagem - Coord. Ana Cardoso de Matos; Portugal: Universidade de Évora, Palácio do Vimioso, sala 205; 2014/Março/28

30 "SESSION 730. Cistercian Studies, III: From Order to Congregation - The Legacy of the Portuguese Cistercian Monasteries within the "International Medieval Congress 2014 - Leeds"; Moderador/Chair: Terryl N. Kinder, Cîteaux: Commentarii Cistercienses; Leeds, Reino Unido: Universidade de Leeds.

Paper 730-a: The Construction of a Portuguese Cistercian Territory: Architecture versus Territory - The Abbey of Alcobaça and Its Domains

Ana M. Tavares Martins, Departamento de Engenharia Civil \& Arquitectura, Universidade da Beira Interior, CITAD, CIDEHUS
} 
Em 2014, estando já a decorrer o Projecto ORFEUS - “A Reforma Tridentina e a música no silêncio claustral: o mosteiro de S. Bento de Cástris" (FCT EXPL/EPHPAT/2253/2013) destaca-se a organização de dois eventos científicos e a participação na

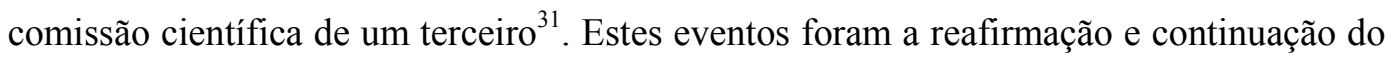
Simpósio Internacional Espaços de Cister e da Residência Cisterciense em S. Bento de Cástris, sendo o primeiro dedicado à Arquitectura e Música ${ }^{32}$ e o segundo dedicado à Estética, o Espaço e o Tempo - Reflexos da Contra-Reforma na praxis musica ${ }^{33}$.

É igualmente em 2014 que são elaboradas na Universidade da Beira Interior e realizadas as provas públicas de duas dissertações de Mestrado, na área científica de Arquitectura (ciclo de estudos integrado), no âmbito do projecto ORFEUS ${ }^{34}$ Com base nestas dissertações e pela constatação de que a igreja do Mosteiro de S. Bento de Cástris apresenta uma tipologia de configuração de espaços pouco comum foi necessário elaborar um ensaio acústico da igreja ${ }^{35}$, explorando as condições acústicas da mesma assim como o estudo do comportamento acústico da Igreja de S. Bento de Cástris. Deste trabalho resultaram artigos e comunicações conjuntas. ${ }^{36}$

Paper 730-b: Cistercian Feminine Monasteries in Portugal as Spaces of Assertion and Power: From the Mystic Marriage to the Management of Everyday Life, Leisure, and Creativity

Antónia Fialho Conde, Departamento de Historia, Universidade de Évora, CIDEHUS

31 "Seminário Internacional Arte, Música e Devoção nos Mosteiros da Ordem da Cister" organizado pela Casa Museu de Monção / Universidade do Minho e pelo Projecto ORFEUS - "A Reforma Tridentina e a música no silêncio claustral: o mosteiro de S. Bento de Cástris" FCT EXPL/EPH-PAT/2253/2013 com apoio do CIDEHUS e das Universidades da Beira Interior, Açores e Évora, Monção -Portugal: Casa Museu de Monção

32 "II SIMPÓSIO INTERNACIONAL ESPAÇOS DE CISTER: ARQUITECTURA e MUSICA" - 2014/Novembro/20-21 - [organizado pelo DECA-UBI, CIDEHUS, CITAD e com apoio da Cîteaux: Commentarii cistercienses e da Câmara Municipal da Covihã]; Covilhã, Portugal: Auditório 8.01 da Faculdade de Engenharia da Universidade da Beira Interior (comissão organizadora Ana Maria Tavares MARTINS, Antónia CONDE, António Santos PEREIRA, Carlos MADALENO e Michael MATHIAS)

33 "II Residência Cisterciense em S. Bento de Cástris - A Estética, o Espaço e o Tempo. Reflexos da Contra-Reforma na praxis musica." - 2014/Setembro/19-20 - [organizadas pelo CIDEHUS, CHAIA, DRCAlentejo]; Évora, Portugal: Mosteiro de S. Bento de Cástris (comissão organizadora Antónia CONDE, Ana Maria Tavares MARTINS, António Camões GOUVEIA, Ana Paula AMENDOEIRA, Aurora CARAPINHA, e Jorge RIVERA)

${ }^{34}$ RODRIGUES, Fabiel Gonçalves; "A Influência da Arquitetura Cisterciense na Arquitetura Religiosa Contemporânea". Área científica Arquitectura / Mestrado Integrado em Arquitectura; Universidade da Beira Interior; Orientador: Ana Maria Tavares Martins, Co-orientador Prof. Doutora Antónia Fialho Conde e REIS, Carla Patricia Lopes dos; "Mosteiro de São Bento de Cástris Música Vs. Arquitectura". Área científica Arquitectura / Mestrado Integrado em Arquitectura; Universidade da Beira Interior; Orientador: Ana Maria Tavares Martins, Co-orientador Prof. Doutora Antónia Fialho Conde

${ }^{35}$ Este trabalho apenas foi possível concretizar-se com a cedência de equipamentos do Laboratório de Saúde na Edificação (LABSED) do Ubimedical.

${ }^{36}$ MARTINS, Ana Maria Tavares, CONDE, Antónia Fialho, REIS, Carla, RODRIGUES, Fabiel e CARLOS, Jorge S.; Contributo para a investigação da Arquitectura Cisterciense em Portugal in "II Simpósio Internacional Espaços de Cister: Arquitectura e Música"; organização DECA-UBI, CIDEHUS, CITAD; 2014/Novembro/20-21; LANZINHA, João, NEPOMUCENO, Miguel, MARTINS, Ana Maria Tavares, REIS, Carla e ALVES, Albino; Avaliação exploratória do comportamento acústico da igreja do mosteiro de S. Bento de Cástris in "II Simpósio Internacional Espaços de Cister: Arquitectura e Música"; organização DECA-UBI, CIDEHUS, CITAD; 2014/Novembro/20-21; REIS, Carla; Mosteiro de São Bento de Castris: Musica vs. Arquitectura in "II Simpósio Internacional Espaços de Cister: Arquitectura e Música"; organização DECA-UBI, CIDEHUS, CITAD; 2014/Novembro/20-21; RODRIGUES, Fabiel; A Influência da Arquitectura Cisterciense na Arquitectura Religiosa Contemporânea in "II Simpósio Internacional Espaços de Cister: Arquitectura e Música"; organização DECA-UBI, CIDEHUS, CITAD; 2014/Novembro/20-21; LANZINHA, João, NEPOMUCENO, Miguel, MARTINS, Ana Maria Tavares, REIS, Carla e ALVES, Albino; Metodologia para avaliação exploratória do 
Como continuação do trabalho desenvolvido está ainda a ser elaborado um estudo da luz natural na Igreja de S. Bento de Cástris e a modelação 3D do Mosteiro de S. Bento de Cástris assim como a sua cerca com conclusão prevista para 2015.

Desta forma a comunicação apresentada reflecte o trabalho desenvolvido no Departamento de Engenharia Civil e Arquitectura da Universidade da Beira Interior, e ainda em curso, no âmbito do Projecto ORFEUS - A Reforma tridentina e a música no silêncio claustral: o mosteiro de S. Bento de Cástris (Projecto FCT EXPL/EPHPAT/2253/2013) tendo sido trazido a debate um contributo para o estudo da especificidade do Mosteiro de S. Bento de Cástris, no contexto da arquitectura cisterciense.

comportamento acústico da igreja do Mosteiro de São Bento de Cástris, Évora in "2a Residência Cisterciense de S. Bento de Cástris - A Estética, o Espaço e o Tempo. Reflexos da Contra-Reforma na praxis musical”; organização Project EXPL/EPH-PAT/2253/2013 ORFEUS - The Tridentine reform and the music in the silence of the cloister: the monastery of S. Bento de Cástris, CIDEHUS, CHAIA e Direcção Regional de Cultura do Alentejo; 2014/Setembro/19-20 